Article

\title{
Evolution of Calcareous Deposits and Passive Film on 304 Stainless Steel with Cathodic Polarization in Sea Water
}

\author{
Tianxiang Sun ${ }^{1,2}$, Guosheng Huang ${ }^{1}$, Ping $\mathrm{Lv}^{2}$, Likun $\mathrm{Xu}^{1, *(\mathbb{D})}$ and Li Ma ${ }^{1}$ \\ 1 State Key Laboratory for Marine Corrosion and Protection, Luoyang Ship Material Research \\ Institute (LSMRI), Qingdao 266237, China; gordon.sun@goertek.com (T.S.); huanggs@sunrui.net (G.H.); \\ mal@sunrui.net (L.M.) \\ 2 School of Civil Engineering, Qingdao University of Technology, Qingdao 266033, China; lvping@qut.edu.cn \\ * Correspondence: xulk@sunrui.net; Tel.: +86-532-6872-5088
}

Received: 18 February 2018; Accepted: 18 May 2018; Published: 21 May 2018

check for updates

\begin{abstract}
The change of protective current density, the formation and growth of calcareous deposits, and the evolution of passive film on 304 stainless steel (SS) were investigated at different potentials of cathodic polarization in sea water. Potentiostatic polarization, electrochemical impedance spectroscopy (EIS), and surface analysis techniques of scanning electron microscopy (SEM), energy dispersive X-ray (EDX) microanalysis and X-ray diffraction (XRD) were used to characterize the surface conditions. It was found that the protective current density was smaller for keeping polarization at $-0.80 \mathrm{~V}$ (vs. saturated calomel electrode (SCE), same as below) than that at $-0.65 \mathrm{~V}$. The calcareous deposits could not be formed on $304 \mathrm{SS}$ with polarization at $-0.50 \mathrm{~V}$ while it was well protected. The formation rate, the morphology, and the constituent of the calcareous deposits depended on the applied potential. The resistance of passive film on 304 SS decreased at the first stage and then increased when polarized at $-0.80 \mathrm{~V}$ and $-0.65 \mathrm{~V}$, which was related to the reduction and the repair of passive film. For the stainless steel polarized at $-0.50 \mathrm{~V}$, the film resistance increased with polarization time, indicating that the growth of oxide film was promoted.
\end{abstract}

Keywords: polarization potential; cathodic protection; 304 stainless steel; calcareous deposit; passive film

\section{Introduction}

Type 304 stainless steel (SS) is often used for facilities and structures exposed in sea water, and is prone to suffering from localized corrosion like pitting and crevice corrosion due to chloride ion attack [1-3]. There are many technologies to protect 304 SS from corrosion in sea water, among which cathodic protection is one of the most effective methods [1,4]. The potential is an important factor to consider for cathodic protection. By shifting the potential negatively from open circuit potential $(\mathrm{OCP})$, the thermodynamic trends of corrosion reaction can be mitigated, the adsorption of aggressive chloride ions can be held back, and the $\mathrm{pH}$ value close to the surface can be elevated [5]. All the above results can exert a positive effect on the anti-corrosive performance of $304 \mathrm{SS}$. However, there is an optimized range of potentials for cathodic protection. The stainless steel cannot achieve effective protection without enough cathodic polarization [1], while it will suffer over-protection when the potential is too negative, even leading to hydrogen embrittlement especially for some high strength materials [6-9]. Although some guidelines on proper potential of cathodic protection can be found in the literature [4,8,10-12], an optimized potential of protection for 304 SS in seawater still needs to be determined with a balanced consideration of cost and effectiveness $[1,3,6]$. 
Corrosion resistance of stainless steels generally comes from the passive film formed on the surface, which depends on the composition, structure, and electrochemical performance of the film. The passive behavior of stainless steel is affected by many factors, such as types of stainless steel, pre-treatment, electrolytes, and applied potentials [13-16]. The reduction of passive film on stainless steel with cathodic polarization at a certain potential will also lead to high risk of corrosion [17].

Cathodic protection often results in the formation of calcareous deposits on the metal surface in sea water [18-23]. The cathodic reactions of dissolved oxygen reduction or water reduction to evolve hydrogen at more negative potential will generate hydroxyl ions, with increasing the $\mathrm{pH}$ value of the electrolyte adjacent to the metal surface, which will promote the formation of calcareous deposits $[19,21-23]$. Some works indicate that $\mathrm{CaCO}_{3}$ is saturated at $\mathrm{pH} 8.7$ or even lower in normal sea water and is ready to deposit as the inorganic carbonic equilibrium in the electrolyte is changed, while the critical $\mathrm{pH}$ value for $\mathrm{Mg}(\mathrm{OH})_{2}$ to deposit is about $9.3[24,25]$. The composition and structure of calcareous deposits can be influenced in a complex manner by many factors, such as environment, applied polarization, and metals of substrate $[5,7,20,25,26]$. The morphologies of calcareous deposits formed under different conditions of cathodic protection for mild steel in sea water were analyzed in detail by Yang et al. [5], who demonstrated that the deposits consisted of inner layer of co-deposited $\mathrm{Mg}(\mathrm{OH})_{2}$ and iron oxide due to the presence of corrosion at the early stage of calcareous deposit formation, and the outer layer of $\mathrm{CaCO}_{3}$ with some $\mathrm{Mg}(\mathrm{OH})_{2}$ precipitated in the pores or cracks.

The insulating calcareous deposits play a very important role in the process of cathodic protection, which can decrease the protective current density, increase the service life of sacrificial anodes, and lower the cost of cathodic protection [27]. However, the formation of calcareous deposits is not always desirable. For example, for moving parts in sea water such as rotating shaft in contact with bearings or hydraulic piston rods, smooth and clean surfaces are needed. In these cases, proper cathodic potential shall be applied not only to protect the parts of stainless steel from corrosion but also to avoid the formation of calcareous deposits on the surfaces.

The formation of calcareous deposits is influenced by many factors, such as temperature, hydrostatic pressure (depth), velocity, chemistry of sea water; current density, potential and period of cathodic polarization; biofilms; substrate materials and surface preparation; and so on [26,28-32]. The precipitated mechanism and the protective property of calcareous deposits on carbon steel substrate have been thoroughly studied $[18,22,30]$. However, only few investigations have focused on the surface of stainless steels under cathodic protection $[1,26,31,32]$. The cathodic polarization should affect the oxide film, change the interfacial environment and cause the development of calcareous deposits on the surface, which make the evolution of surface conditions of stainless steel in sea water much more complicated than that of carbon steel. Limited knowledge is acquired with the modifications of passive film in combination with calcareous deposits on stainless steel under different cathodic polarization in sea water. Obtaining a better understanding of the evolution of passive film and calcareous deposits on stainless steel with potential and time of polarization is of great significance to ascertain the effective protection and improve the corrosion resistance of stainless steels in sea water.

In the present work, a comprehensive investigation with cathodic polarization at different potentials was carried out on 304 SS in sea water. Electrochemical impedance spectroscopy (EIS) was used to characterize the surface variation of 304 SS under polarization. Scanning electron microscopy (SEM), energy dispersive X-ray (EDX) microanalysis, and X-ray Diffraction (XRD) were used to investigate the formation of calcareous deposits. The evolution of calcareous deposits and passive film on the surface of 304 SS was discussed.

\section{Experimental}

\subsection{Electrode Preparation}

The test material used in the experiment was 304 SS sheet of $2 \mathrm{~mm}$ in thickness from Shanxi Tai Gang Stainless Steel Co. Ltd. (Taiyuan, China) with a composition as follows (wt \%): C 0.06, Si 0.54, 
Mn 0.90, P 0.040, S 0.017, Cr 18.48, Ni 8.06, and Fe balance. The test samples were cut from the sheet into pieces with the dimension of $20 \mathrm{~mm} \times 20 \mathrm{~mm} \times 2 \mathrm{~mm}$, sealed with epoxy resin, leaving an area of $10 \mathrm{~mm} \times 10 \mathrm{~mm}$ exposed. The working surface was ground using silicon carbide abrasive paper to 1500 grit, then rinsed with distilled water, and dried in air.

\subsection{Test Solution}

Test solution was natural sea water from the Yellow Sea taken from the corrosion test site of Qingdao, with a salinity of $33.4 \%$ and a $\mathrm{pH}$ value of 7.6. The solution was in a quiescent condition. The temperature was controlled at $(25 \pm 1)^{\circ} \mathrm{C}$ in a water bath, the oxygen concentration was controlled at $8 \mathrm{mg} / \mathrm{L}$ by purging certain amounts of oxygen and nitrogen. The oxygen concentration was calibrated by a Polymetron 9582 dissolved oxygen detector (Hach Company, Loveland, CO, USA).

\subsection{Electrochemical Tests}

Electrochemical tests included potentiodynamic polarization test, potentiostatic test and EIS measurement. The potentiodynamic polarization curve was recorded at a scanning rate of $20 \mathrm{mV} / \mathrm{min}$, in the potential range from about $-600 \mathrm{mV}$ (vs. OCP) to $+450 \mathrm{mV}$ (vs. OCP). The potentiostatic polarizations were conducted at the potential of $-0.50 \mathrm{~V}$ (vs. saturated calomel electrode (SCE), same as below), $-0.65 \mathrm{~V}$, and $-0.80 \mathrm{~V}$ respectively, and the changes of current density were measured. EIS spectra were recorded at intervals of cathodic polarization as well as at the beginning without polarization to characterize the surface conditions. The EIS test was taken at the steady potential that the specimen had immediately prior to conducting the measurement, without decaying back to a natural potential [5]. The impedance spectra were measured in the frequency range from $100 \mathrm{kHz}$ to $10 \mathrm{mHz}$ with 49 points recorded, the disturbing signal is a sinusoidal wave with an amplitude of $\pm 10 \mathrm{mV}$. Each single experiment has three parallel samples for testing.

All the electrochemical tests were performed using a PARSTAT 2273 workstation (Princeton Applied Research, Oak Ridge, TN, USA) in a conventional three electrodes system with Pt as counter electrode, SCE as the reference electrode and the 304 SS as the working electrode. The data were analyzed with C-View and ZSimpWin softwares (Princeton Applied Research, Oak Ridge, TN, USA).

\subsection{SEM and XRD Analysis}

The surface morphologies and elements of the samples after cathodic polarization were analyzed using a Zeiss Ultra-55 field-emission scanning electronic microscope (Carl Zeiss, Oberkochen, Germany) equipped with an EDX analyzer. The surface phases of the samples after cathodic polarization were detected using XRD (Bruker D8, Karlsruhe, Germany) by $\mathrm{Cu}-\mathrm{K} \alpha \alpha_{1}$ radiation with $\lambda=0.15406 \mathrm{~nm}$.

\section{Results and Discussion}

\subsection{Polarization Tests}

Figure 1 shows a typical potentiodynamic polarization curve of 304 SS in natural seawater. The initial open circuit potential ( $\left.E_{\text {corr }}\right)$ of 304 SS in sea water was $-0.36 \mathrm{~V}$. The suitable potential range for cathodic protection of the stainless steel can be determined from the potentiodynamic polarization curve. The most positive potential is the potential $E_{\mathrm{p}}$ at which oxygen concentration polarization begins, and the most negative potential $E_{\max }$ is the potential when hydrogen evolution occurs. As for $304 \mathrm{SS}$, the potential of protection ranged from $-0.48 \mathrm{~V}\left(E_{\mathrm{p}}\right)$ to $-0.83 \mathrm{~V}\left(E_{\max }\right)$ derived from Figure 1 . To investigate the effect of cathodic protection on the formation of calcareous deposits on the stainless steel, the potentials for the potentiostatic polarization were selected at $-0.50 \mathrm{~V},-0.65 \mathrm{~V}$, and $-0.80 \mathrm{~V}$ respectively. The most negative potential is a slightly positive than $-0.83 \mathrm{~V}$ due to avoiding the effect of hydrogen evolution. 


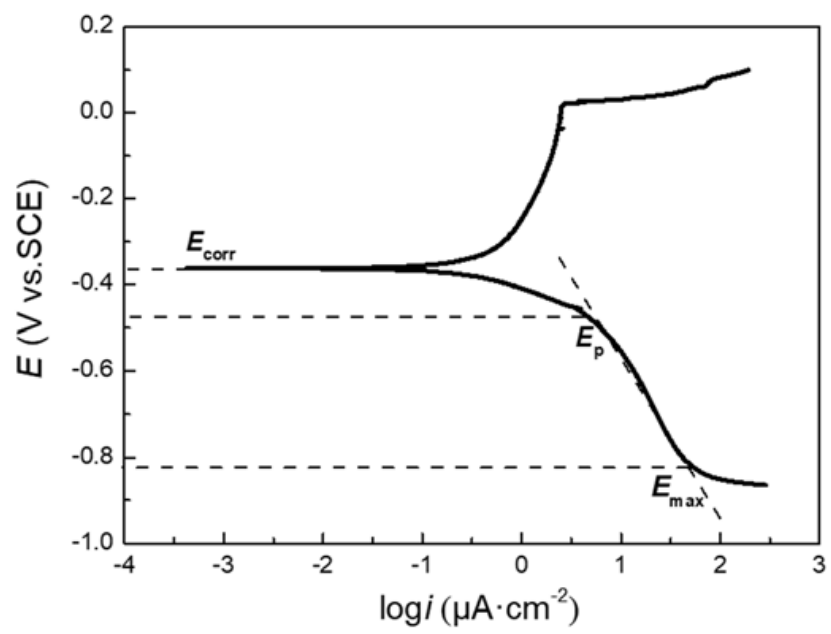

Figure 1. Potentiodynamic polarization curve of 304 stainless steel (SS) in seawater.

The variation of current density with time to maintain a certain potential on 304 SS in natural seawater is shown in Figure 2. At the initial stage of polarization, the protective current density was high, then decreased to a stable value. It took about $80 \mathrm{~h}$ to reach a relatively stable current density when the polarization potential was $-0.65 \mathrm{~V}$, while it needed only $30 \mathrm{~h}$ to achieve stable current density as for the polarization at $-0.50 \mathrm{~V}$ and $-0.80 \mathrm{~V}$. The current density required for maintaining a polarization potential, which was averaged with three parallel samples, was about $5.1 \mu \mathrm{A} \cdot \mathrm{cm}^{-2}, 6.5 \mu \mathrm{A} \cdot \mathrm{cm}^{-2}$, and $3.1 \mu \mathrm{A} \cdot \mathrm{cm}^{-2}$ with polarization at $-0.80 \mathrm{~V},-0.65 \mathrm{~V}$, and $-0.50 \mathrm{~V}$ respectively. The smallest current density at $-0.50 \mathrm{~V}$ shall be attributed to the most positive potential under cathodic polarization. It is interesting that the stable current density needed for polarization at $-0.80 \mathrm{~V}$ is smaller than that at $-0.65 \mathrm{~V}$.

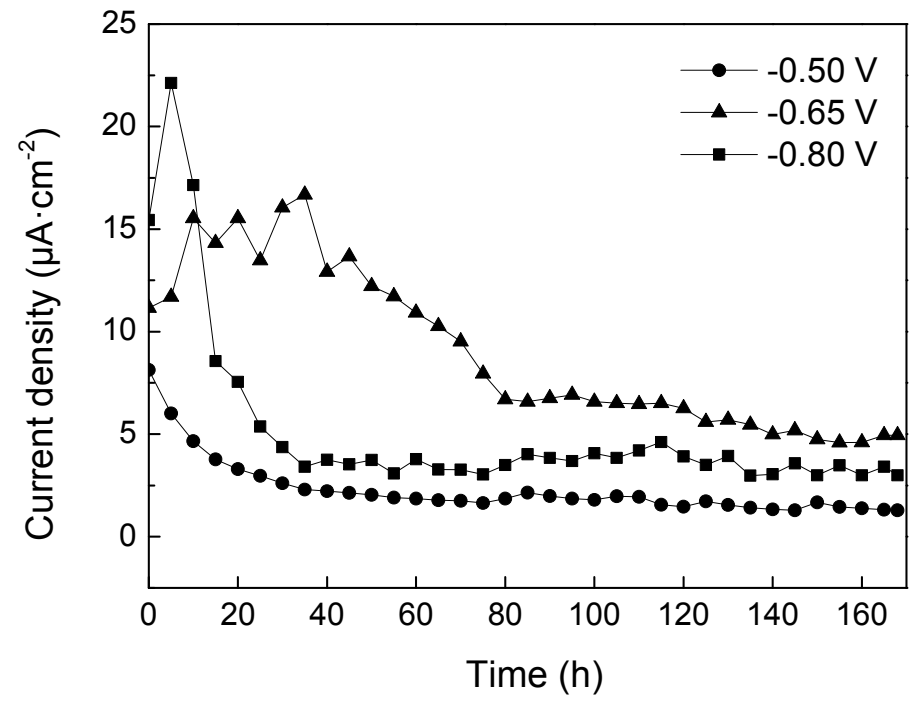

Figure 2. Variation of current density with potentiostatic polarization of 304 SS at different cathodic potentials in seawater.

Generally, current density is determined by the reaction rate occurring at the interface of electrode. In this 304 SS electrode system, several factors can affect the reaction rate, including the electrochemical reactions, the concentration of reactants and the transportation of reactants and products. The current density will decrease to a stable value as a result of the consumption of reactants and the formation of barrier layer. There are two possible reactions within the tested potentials, one is the reduction of 
passive film, another is the reduction of oxygen. The transportation processes could be influenced by the barrier layer (calcareous deposits) since the oxygen concentration is controlled in bulk solution in this study. Then, the variation of current density shall be related to the effect of calcareous deposits and the variance of oxide film formed on the stainless steel with polarization at different potentials, which will be discussed later. It is also worth noting that there exists a current density increase at the initial stage for $-0.65 \mathrm{~V}$ and $-0.80 \mathrm{~V}$, which may be attributed to the reduction of passive film on 304 SS [33-37]. The prompt decrease of current density initially with polarization at $-0.50 \mathrm{~V}$ can be attributed to the consumption of oxygen if the passive film is not reduced at this potential [9]. Finally, the current densities decreased to a relatively stable value at all the three potentials.

\subsection{EIS Measurement}

\subsubsection{EIS Evolution of 304 SS with Polarization at $-0.80 \mathrm{~V}$}

EIS was used to monitor the evolution of surface conditions of 304 SS after different period of cathodic polarization in sea water. EIS is a very valuable technique for the indirect characterization of the passive film and the calcareous deposits on the surface of stainless steel [26,30-32,38]. Figure 3 shows the EIS spectra of $304 \mathrm{SS}$ after polarization at $-0.80 \mathrm{~V}$ in sea water for different times. It can be seen that the EIS evolution can be divided into two stages during the $168 \mathrm{~h}$ test period, with at least two obvious semi-circles appeared in the Nyquist plots after $20 \mathrm{~h}$ of polarization. To understand the EIS results, equivalent circuits were adopted to analyze the spectra based on the structure of the electrode and the process occurring on the surface as shown in Figure 4. The measured data and the simulation data were presented in the same plot. The simulated lines fit well with the measured data, which means that the equivalent circuits are reasonable.
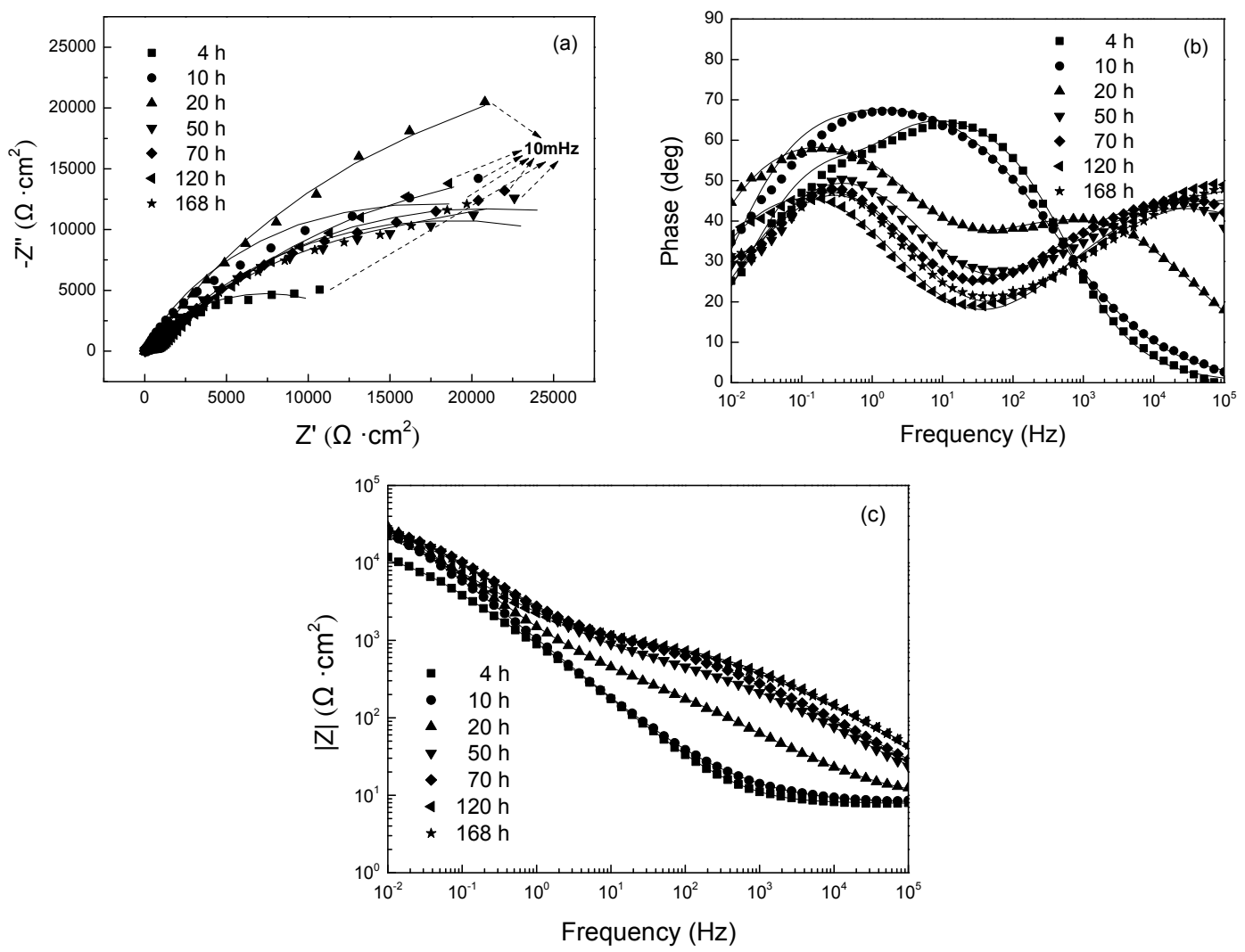

Figure 3. EIS evolution of 304 SS with polarization at $-0.80 \mathrm{~V}$ in sea water. Nyquist plot (a), Bode plot $(\mathbf{b}, \mathbf{c})$, in which symbols are measured data, lines are simulated. 
(a)

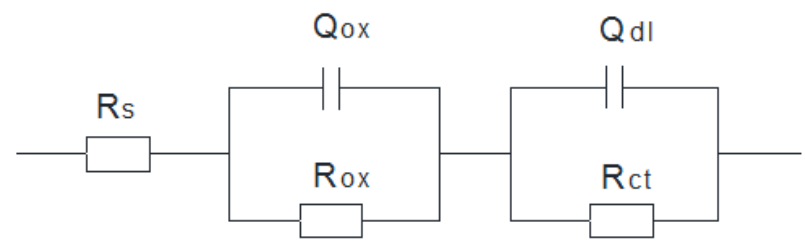

(b)

$Q_{c}$

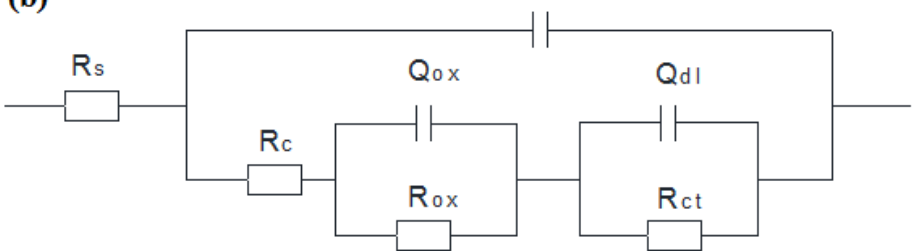

(c)

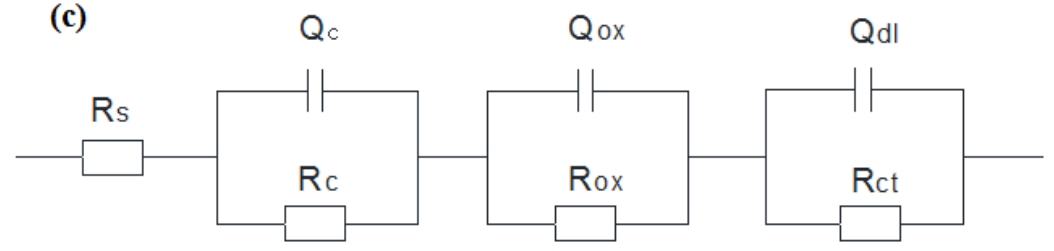

Figure 4. Equivalent electrical circuits (EECs) used for simulating the EIS spectra of 304 SS in seawater after cathodic polarization at different potential. EEC used at the first stage of polarization (a), at the second stage with imperfect calcareous deposits (b), and at the later stage with complete calcareous deposits (c).

At the first stage before the 10 -h polarization, Figure $4 \mathrm{a}$ is considered to be suitable for representing the electrode processes, which are dominated by the corrosion reaction of metal and the effect of passive film $[30,39,40]$. At the second stage after that time, a new semi-circle appeared at the high frequency region in the Nyquist plot as shown in Figure 3a, which is related to the produced calcareous deposits. The equivalent electrical circuit in Figure $4 \mathrm{~b}$ can be used with three time constants, attributed to the corrosion reaction, the passive film and the imperfect calcareous deposits respectively. As the polarization time increased (after $50 \mathrm{~h}$ ), the calcareous deposits became complete and compact, leading to the shift of the phase angle peak to higher frequency (see Figure 3b). At this stage, the equivalent circuit in Figure $4 \mathrm{c}$ is thought to be more suitable for representing the electrode structure. In the equivalent electrical circuits, $R_{\mathrm{s}}$ is the solution resistance, $R_{\mathrm{ox}}$ is the resistance of passive film, $Q_{\mathrm{ox}}$ is the capacitance of passive film, $R_{\mathrm{ct}}$ is the charge transfer resistance, $Q_{\mathrm{dl}}$ is the double layer capacitance, $R_{\mathrm{c}}$ is the resistance of calcareous deposits, and $Q_{\mathrm{c}}$ is the capacitance of calcareous deposits. The constant phase element $Q$ is used instead of capacitance $C$ to get a more ideal simulation result due to the dispersion effect from the rough electrode surface [30].

The EIS fitted results of 304 SS electrode under polarization at $-0.80 \mathrm{~V}$ in sea water are listed in Table $1 . R_{\mathrm{ct}}$ reflects the corrosion resistance of 304 SS in sea water. The corrosion resistance of stainless steel depends on the protective layer of thin oxide film formed on the surface, which has limited ionic and electronic conductivity, and can significantly lower the electrochemical reaction rates on the surface [2,30]. The $R_{\mathrm{ct}}$ decreased from $199 \mathrm{k} \Omega \cdot \mathrm{cm}^{2}$ without cathodic polarization to $14.48 \mathrm{k} \Omega \cdot \mathrm{cm}^{2}$ with polarization for $4 \mathrm{~h}$, then gradually increased with the polarization going on, and reached $130.6 \mathrm{k} \Omega \cdot \mathrm{cm}^{2}$ at $168 \mathrm{~h}$ after polarization. The fast decrease of $R_{\mathrm{ct}}$ at the first stage may be related to the degradation of the oxide film on the surface of 304 SS with cathodic polarization at $-0.80 \mathrm{~V}$ [41]. The following increase of $R_{\mathrm{ct}}$ gradually may be attributed to the repair of the passive film because of the alkaline environment formed due to cathodic polarization [42,43]. 
Table 1. Fitting parameters for EIS spectra of 304 SS under polarization at $-0.80 \mathrm{~V}$.

\begin{tabular}{|c|c|c|c|c|c|c|c|c|c|c|}
\hline $\begin{array}{c}t \\
\text { (h) }\end{array}$ & $\begin{array}{c}R_{\mathrm{s}} \\
\left(\Omega \cdot \mathrm{cm}^{2}\right)\end{array}$ & $\underset{\left(\mu \mathrm{F} \cdot \mathrm{cm}^{2}\right)}{Q_{\mathrm{d} l}}$ & $n_{1}$ & $\begin{array}{c}R_{\mathrm{ct}} \\
\left(\mathrm{k} \Omega \cdot \mathrm{cm}^{2}\right)\end{array}$ & $\underset{\left(\mu \mathrm{F} \cdot \mathrm{cm}^{2}\right)}{Q_{\mathrm{c}}}$ & $n_{2}$ & $\begin{array}{c}R_{\mathrm{c}} \\
\left(\Omega \cdot \mathrm{cm}^{2}\right)\end{array}$ & $\underset{\left(\mu \mathrm{F} \cdot \mathrm{cm}^{2}\right)}{Q_{o x}}$ & $n_{3}$ & $\begin{array}{c}R_{\mathrm{ox}} \\
\left(\Omega \cdot \mathrm{cm}^{2}\right)\end{array}$ \\
\hline 0 & 7.773 & 52.49 & 0.854 & 199.0 & - & - & - & 469.2 & 0.768 & 463.9 \\
\hline 4 & 7.833 & 326.1 & 0.736 & 14.48 & - & - & - & 759.3 & 0.918 & 196.1 \\
\hline 10 & 7.924 & 226.6 & 0.781 & 34.45 & - & - & - & 304.7 & 0.488 & 15.28 \\
\hline 20 & 8.780 & 104.4 & 0.905 & 42.29 & 294.9 & 0.475 & 2459 & 102.9 & 0.575 & 363.7 \\
\hline 50 & 3.617 & 172.5 & 0.587 & 48.32 & 443.3 & 0.999 & 4495 & 34.79 & 0.545 & 489.6 \\
\hline 70 & 2.736 & 184.8 & 0.577 & 60.53 & 392.4 & 0.940 & 5731 & 27.22 & 0.545 & 797.2 \\
\hline 120 & 1.016 & 173.5 & 0.641 & 58.54 & 313.2 & 0.652 & 4761 & 18.69 & 0.598 & 634.8 \\
\hline 168 & 2.933 & 229.8 & 0.517 & 130.6 & 323.5 & 0.924 & 7290 & 18.25 & 0.537 & 725.6 \\
\hline
\end{tabular}

$R_{\mathrm{c}}$ is associated with the calcareous deposits. After $20 \mathrm{~h}$ of cathodic polarization at $-0.80 \mathrm{~V}$, $R_{\mathrm{c}}$ began to appear and increased from $2459 \Omega \cdot \mathrm{cm}^{2}$ to $7290 \Omega \cdot \mathrm{cm}^{2}$ at the end of the whole polarization period, which can be ascribed to the formation and growth of the calcareous deposits.

The passive film resistance $R_{\mathrm{ox}}$ decreased very fast at the first stage of cathodic polarization from $463.9 \Omega \cdot \mathrm{cm}^{2}$ without polarization down to $15.28 \Omega \cdot \mathrm{cm}^{2}$ of polarized sample for $10 \mathrm{~h}$, and then increased gradually to $489.6 \Omega \cdot \mathrm{cm}^{2}$ which is close to the oxide film resistance of unpolarized sample. With further cathodic polarization, $R_{\text {ox }}$ continued to increase and got to $725.6 \Omega \cdot \mathrm{cm}^{2}$ at the end of the polarization test.

\subsubsection{EIS Evolution of 304 SS with Polarization at $-0.65 \mathrm{~V}$}

Figure 5 shows the EIS evolution of 304 SS under polarization at $-0.65 \mathrm{~V}$ in seawater. It can be seen that the EIS evolution can be divided into two stages during the 168 -h test period, which is similar to that for polarization at $-0.80 \mathrm{~V}$.
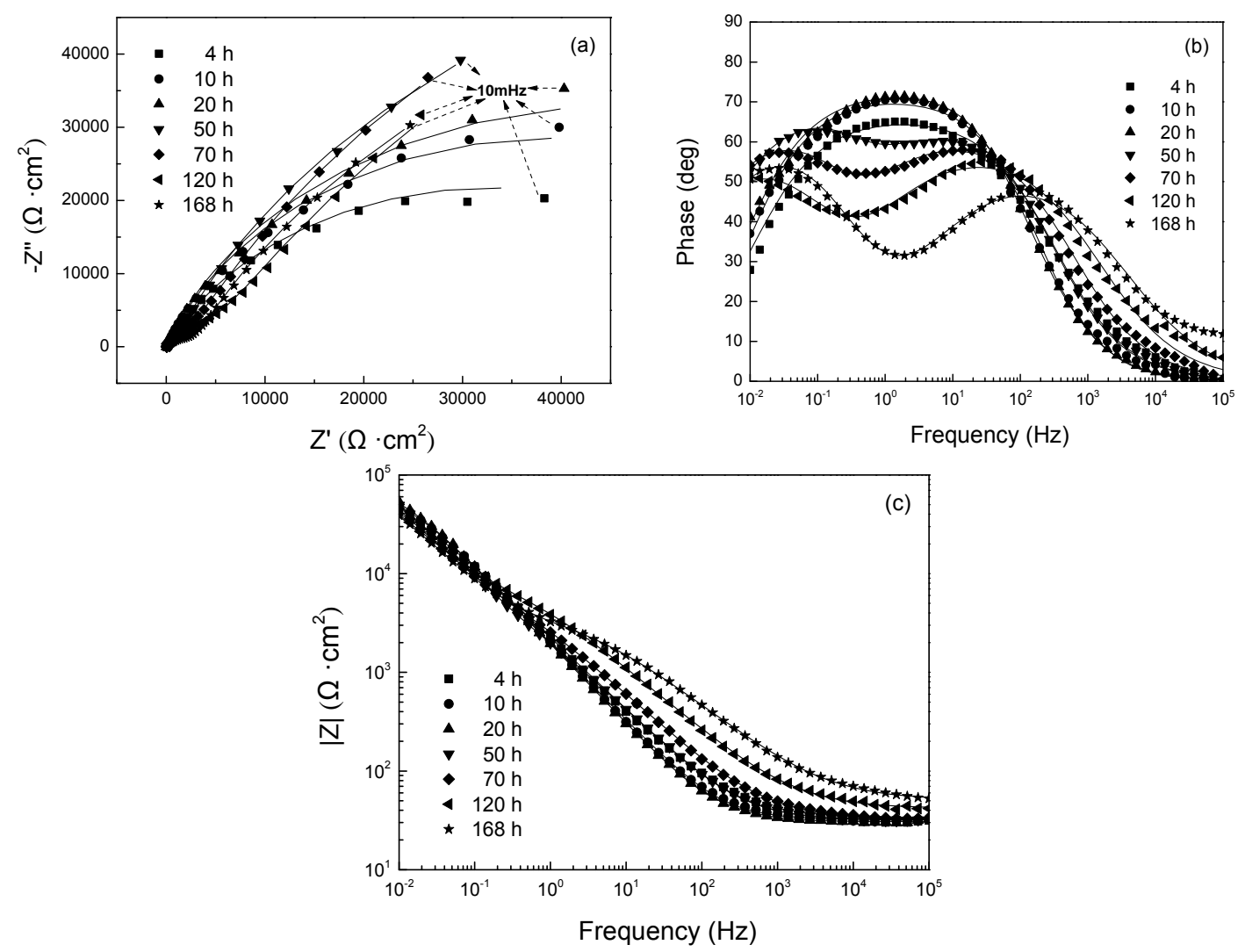

Figure 5. EIS evolution of 304 SS under polarization at $-0.65 \mathrm{~V}$ in sea water. Nyquist plot (a), Bode plot $(\mathbf{b}, \mathbf{c})$, in which symbols are measured data, lines are simulated data. 
After $50 \mathrm{~h}$ of polarization at $-0.65 \mathrm{~V}$, a new dispersed capacitance loop was present in the Nyquist plot in a high frequency region, which was caused by the calcareous deposits. As compared with the EIS spectra at $-0.80 \mathrm{~V}$, the corresponding peaks of phase angle positioned close to middle frequency, suggesting the deposits produced with polarization at $-0.80 \mathrm{~V}$ should be more protective.

The equivalent electrical circuits in Figure 4a,c were used to simulate the EIS spectra for different polarization period. The fitted values for elements in the equivalent circuit of 304 SS under polarization at $-0.65 \mathrm{~V}$ are listed in Table 2 . The charge transfer resistance $R_{\mathrm{ct}}$ decreased at the first stage and then increased with further cathodic polarization, showing similar trend to that under polarization at $-0.80 \mathrm{~V}$. This variation can also be explained with the reduction and repair of passive film during the process of cathodic polarization. At the later stage of polarization, the $R_{\mathrm{ct}}$ values at $-0.65 \mathrm{~V}$ are larger than those at $-0.80 \mathrm{~V}$, suggesting the stainless steel polarized at $-0.65 \mathrm{~V}$ be more corrosion resistant in sea water.

Table 2. Fitting parameters for EIS spectra of 304 SS under polarization at $-0.65 \mathrm{~V}$.

\begin{tabular}{|c|c|c|c|c|c|c|c|c|c|c|}
\hline $\begin{array}{c}t \\
\text { (h) }\end{array}$ & $\begin{array}{c}R_{\mathrm{S}} \\
\left(\Omega \cdot \mathrm{cm}^{2}\right)\end{array}$ & $\underset{\left(\mu \mathrm{F} \cdot \mathrm{cm}^{2}\right)}{Q_{\mathrm{dl}}}$ & $n_{1}$ & $\begin{array}{c}R_{\mathrm{ct}} \\
\left(\mathrm{k} \Omega \cdot \mathrm{cm}^{2}\right)\end{array}$ & $\underset{\left(\mu \mathrm{F} \cdot \mathrm{cm}^{2}\right)}{Q_{\mathrm{c}}}$ & $n_{2}$ & $\begin{array}{c}R_{\mathrm{c}} \\
\left(\Omega \cdot \mathrm{cm}^{2}\right)\end{array}$ & $\underset{\left(\mu \mathrm{F} \cdot \mathrm{cm}^{2}\right)}{Q_{o x}}$ & $n_{3}$ & $\begin{array}{c}R_{\mathrm{ox}} \\
\left(\Omega \cdot \mathrm{cm}^{2}\right)\end{array}$ \\
\hline 0 & 27.77 & 107.5 & 0.819 & 105.1 & - & - & - & 69.76 & 0.840 & 198.6 \\
\hline 4 & 30.80 & 102.4 & 0.776 & 76.61 & - & - & - & 585.8 & 0.622 & 42.14 \\
\hline 10 & 31.00 & 123.5 & 0.799 & 59.58 & - & - & - & 223.5 & 0.815 & 4.697 \\
\hline 20 & 30.72 & 149.9 & 0.785 & 26.62 & - & - & - & 386.2 & 0.998 & 5.306 \\
\hline 50 & 31.17 & 155.2 & 0.789 & 146.9 & 289.1 & 0.707 & 911.4 & 31.32 & 0.998 & 1.483 \\
\hline 70 & 32.49 & 172.2 & 0.761 & 189.6 & 145.3 & 0.706 & 2261 & 8.164 & 0.993 & 3.329 \\
\hline 120 & 38.02 & 163.8 & 0.678 & 281.8 & 69.34 & 0.696 & 3675 & 23.34 & 0.730 & 9.879 \\
\hline 168 & 29.97 & 159.1 & 0.637 & 281.4 & 35.13 & 0.655 & 2861 & 5.073 & 0.572 & 37.76 \\
\hline
\end{tabular}

The EIS analysis demonstrated that the calcareous deposits began to be formed obviously after $50 \mathrm{~h}$ of polarization at $-0.65 \mathrm{~V}$. The resistance of the deposits $R_{\mathrm{c}}$ increased with polarization from $911 \Omega \cdot \mathrm{cm}^{2}$ at $50 \mathrm{~h}$ to $2861 \Omega \cdot \mathrm{cm}^{2}$ at $168 \mathrm{~h}$, owing to the growth of the calcareous deposits. However, the $R_{\mathrm{c}}$ values at $-0.65 \mathrm{~V}$ are smaller than those for polarization at $-0.80 \mathrm{~V}$, which implies that the deposits formed at $-0.65 \mathrm{~V}$ are not so protective.

The film resistance $R_{\mathrm{ox}}$ presented a similar change to the $R_{\mathrm{ct}}$, also decreasing at the first stage and then increasing. This change can be related to the reduction and the repair of the oxide film under polarization at $-0.65 \mathrm{~V}$. It is interesting that the sample polarized at $-0.65 \mathrm{~V}$ has smaller $R_{\mathrm{ox}}$ than the one at $-0.80 \mathrm{~V}$, probably because the passive film modified under polarization at $-0.65 \mathrm{~V}$ is more conductive [13]. The oxide film with lower resistance and the more porous calcareous deposits make the current density of $304 \mathrm{SS}$ required to maintain polarization at $-0.65 \mathrm{~V}$ even higher than that at $-0.80 \mathrm{~V}$ (see Figure 2).

\subsubsection{EIS Evolution of 304 SS with Polarization at $-0.50 \mathrm{~V}$}

Figure 6 shows the EIS evolution of 304 SS with polarization at $-0.50 \mathrm{~V}$ in seawater. It can be seen that the EIS spectra have quite similar characteristic throughout the test period. At this polarization potential, the capacitance arc in the Nyquist plot attributed to the calcareous deposits cannot be found.

The equivalent circuit in Figure $4 \mathrm{a}$ is suitable for representing the electrode process, which is dominated by the corrosion reaction of metal and the change of the passive film. The fitting results of EIS for $304 \mathrm{SS}$ with polarization at $-0.50 \mathrm{~V}$ are listed in Table 3. As polarization went on, both $R_{\mathrm{ox}}$ and $R_{\mathrm{ct}}$ increased continuously. It can be inferred that passive film will not be reduced under polarization at $-0.50 \mathrm{~V}[9,15]$. With the polarization at $-0.50 \mathrm{~V}$, the dominant cathodic reaction on the surface of 304 SS is the oxygen reduction. The cathodic polarization can inhibit the adsorption of chloride ions on the surface, so the passive film will not be attacked. The cathodic polarization at $-0.50 \mathrm{~V}$ will enhance the $\mathrm{pH}$ value of the electrolyte adjacent to the surface, which may promote the growth of the oxide film, but not be high enough to lead to the formation of calcareous deposits. The large $R_{\mathrm{ox}}$ and $R_{\mathrm{ct}}$ values demonstrate that type 304 stainless steel with cathodic polarization at $-0.50 \mathrm{~V}$ can have good 
corrosion resistance in sea water. Note that there are some differences among the ground samples without polarization for EIS testing immersed in sea water, which indicates that it is difficult to get the same surface condition of passive film on 304 SS with only abrasive grinding.
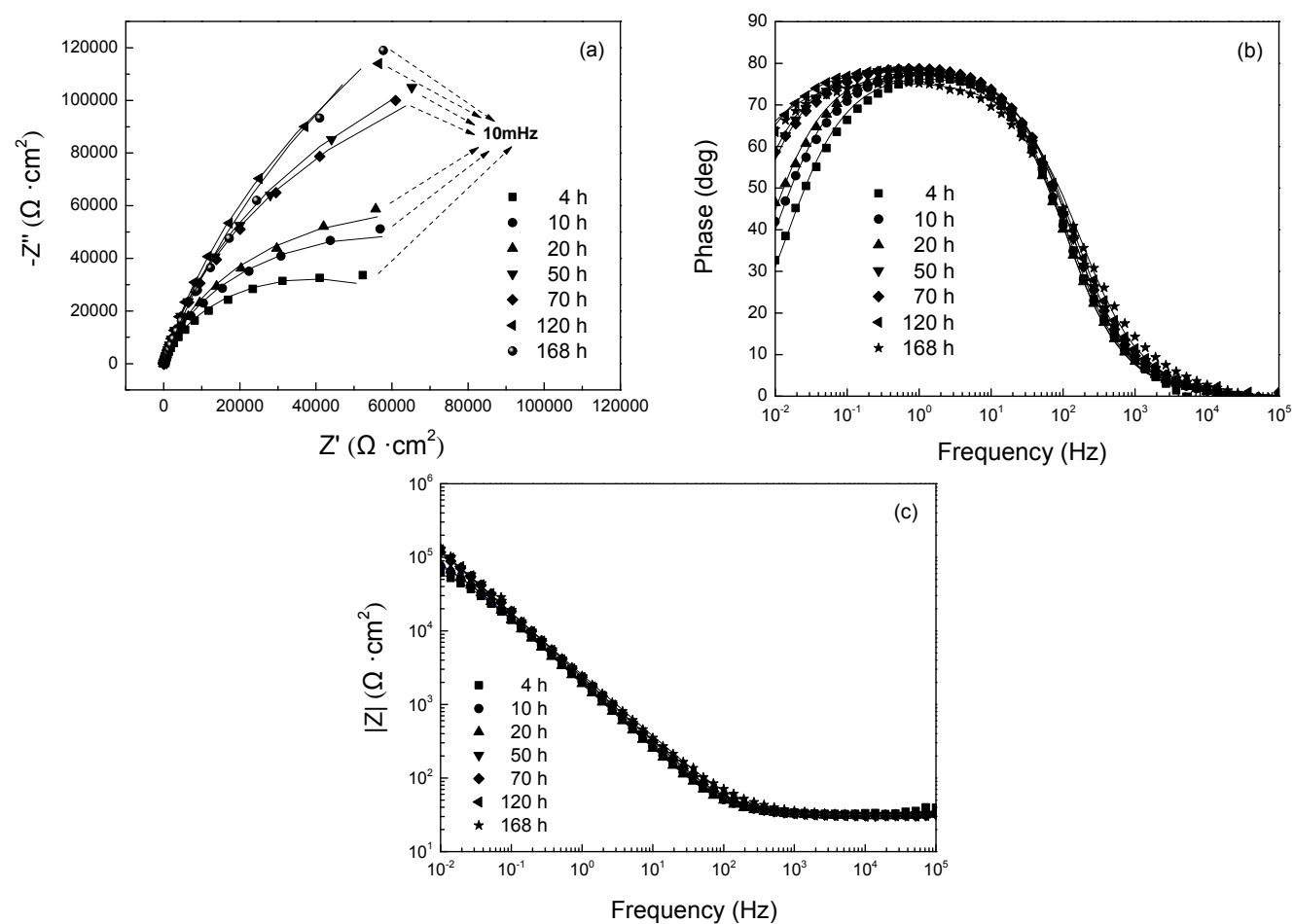

Figure 6. EIS evolution of $304 \mathrm{SS}$ under the polarization potential of $-0.50 \mathrm{~V}$ in sea water. Nyquist plot (a), Bode plot $(\mathbf{b}, \mathbf{c})$, in which symbol are measured data, line are simulated data.

Table 3. Fitting parameters for EIS spectra of 304 SS under polarization at $-0.50 \mathrm{~V}$.

\begin{tabular}{cccccccc}
\hline $\begin{array}{c}\boldsymbol{t} \\
\mathbf{h})\end{array}$ & $\begin{array}{c}\boldsymbol{R}_{\mathbf{s}} \\
\left(\boldsymbol{\Omega} \cdot \mathbf{c m}^{\mathbf{2}}\right)\end{array}$ & $\begin{array}{c}Q_{\mathrm{dl}} \\
\left(\mu \mathbf{F} \cdot \mathbf{c m}^{\mathbf{2}}\right)\end{array}$ & $\boldsymbol{n}_{\mathbf{1}}$ & $\begin{array}{c}\boldsymbol{R}_{\mathrm{ct}} \\
\left(\mathbf{k} \boldsymbol{\Omega} \cdot \mathbf{c m}^{\mathbf{2}}\right)\end{array}$ & $\begin{array}{c}\boldsymbol{Q}_{\mathbf{o x}} \\
\left(\mu \mathbf{F} \cdot \mathbf{c m}^{\mathbf{2}}\right)\end{array}$ & $\boldsymbol{n}_{\mathbf{3}}$ & $\begin{array}{c}\boldsymbol{R}_{\mathbf{o x}} \\
\left(\boldsymbol{\Omega} \cdot \mathbf{c m}^{\mathbf{2}}\right)\end{array}$ \\
\hline 0 & 28.14 & 31.75 & 0.768 & 29.86 & 84.23 & 0.848 & 168.9 \\
4 & 34.18 & 112.7 & 0.885 & 78.12 & 645.8 & 0.869 & 222.8 \\
10 & 31.28 & 183.9 & 0.830 & 88.54 & 192.2 & 0.980 & 2306 \\
20 & 30.79 & 205.4 & 0.998 & 95.18 & 232.5 & 0.810 & 17420 \\
50 & 31.21 & 140.8 & 0.998 & 181.5 & 221.3 & 0.783 & 20640 \\
70 & 31.21 & 159.5 & 0.999 & 219.4 & 175.2 & 0.820 & 32060 \\
120 & 30.41 & 126.1 & 0.974 & 335.9 & 236.2 & 0.773 & 32800 \\
168 & 31.51 & 124.5 & 0.989 & 286.6 & 206.0 & 0736 & 22510 \\
\hline
\end{tabular}

\subsection{Surface Analysis}

\subsubsection{SEM Analysis}

Figure 7 shows the SEM morphologies of $304 \mathrm{SS}$ after polarization at $-0.80 \mathrm{~V}$ for $20 \mathrm{~h}, 70 \mathrm{~h}$, and $168 \mathrm{~h}$. Some scattered crystal particles of calcareous deposit were found on the sample surface after $20 \mathrm{~h}$ polarization at $-0.80 \mathrm{~V}$. These particles were coarse and in the shape of corn. Only part of the surface was covered by the deposits. The calcareous deposits became complete and covered all the surface of the sample at the polarization time of $70 \mathrm{~h}$, while the deposits formed with polarization for $168 \mathrm{~h}$ were more compact and thicker. It seems that the later deposits are growing on the bases of the early formed particles, blocking the gaps between the corn-like particles. 

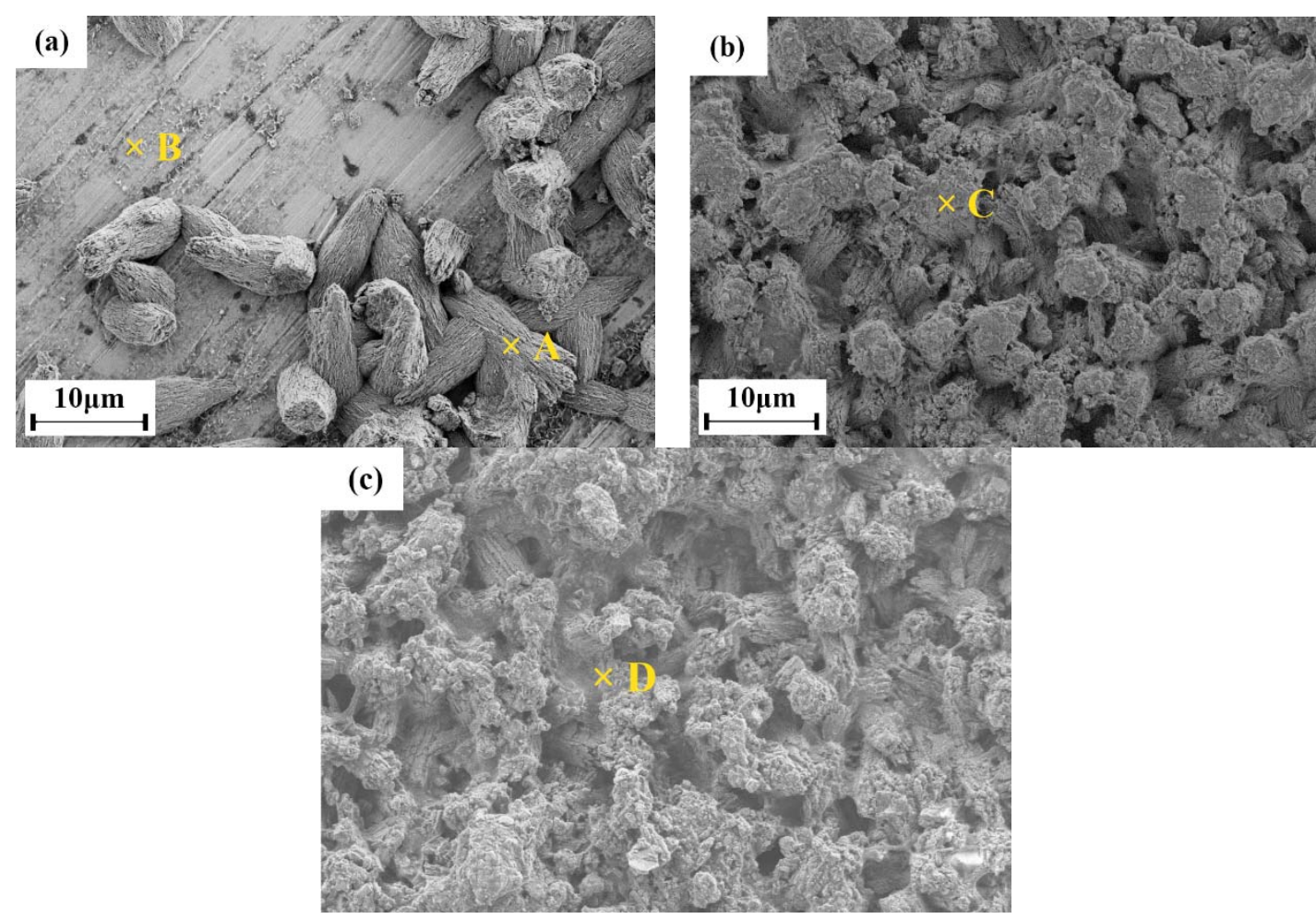

Figure 7. Surface morphology of $304 \mathrm{SS}$ with polarization at $-0.80 \mathrm{~V}$ in sea water for $20 \mathrm{~h} \mathrm{(a),} 70 \mathrm{~h} \mathrm{(b)}$ and $168 \mathrm{~h}(\mathbf{c})$.

After $20 \mathrm{~h}$ polarization at $-0.65 \mathrm{~V}$, a small calcareous deposit can be found only on part of the sample surface as shown in Figure 8. The deposits were composed of fine particles and covered only quite a small area. Therefore, the EIS spectrum with polarization at $20 \mathrm{~h}$ did not present the time constant at high frequency related to the calcareous deposits (see Figure 5). With polarization at $-0.65 \mathrm{~V}$ for $70 \mathrm{~h}$, the calcareous deposits covered the whole surface, where a lot of corn-like coarse particles stacked together. After $168 \mathrm{~h}$ of polarization at $-0.65 \mathrm{~V}$, the deposits became thicker and the flower-like top deposits with a lot of small crystals were grown on the base scale.

In comparison with the morphology of the calcareous deposits under polarization at $-0.80 \mathrm{~V}$, the deposits formed at $-0.65 \mathrm{~V}$ have a microstructure with more gaps and holes. These porous deposits will decrease the resistance and be less protective, which is consistent with the results of EIS analysis and chronoamperometry measurement.

Figure 9 shows the morphology of 304 SS with polarization at $-0.50 \mathrm{~V}$ for different time. The surface of 304 SS was clean without any corrosion, and no calcareous deposits were found throughout the polarization period at $-0.50 \mathrm{~V}$.

The surface SEM morphology variation of 304 SS immersed in sea water without polarization was also observed. It was found that pitting corrosion occurred on some 304 SS samples after immersion in sea water for $168 \mathrm{~h}$, because the passive film is easily attacked by chloride ions. The results illustrate that the cathodic polarization at $-0.50 \mathrm{~V}$ can provide effective cathodic protection for $304 \mathrm{SS}$ exposed in sea water. 

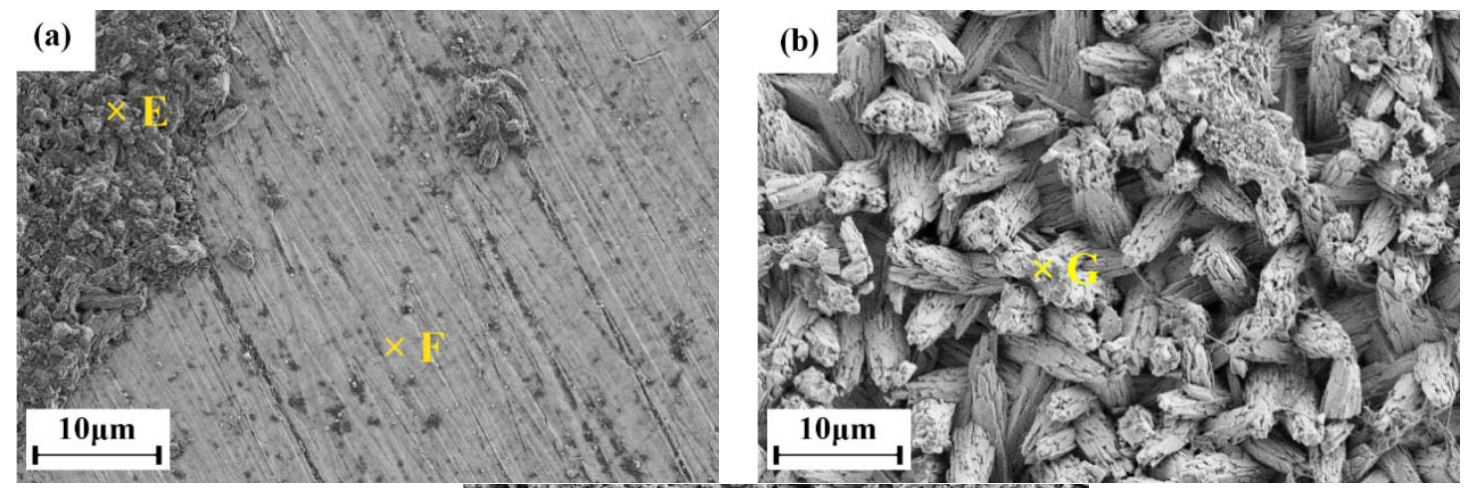

(c)

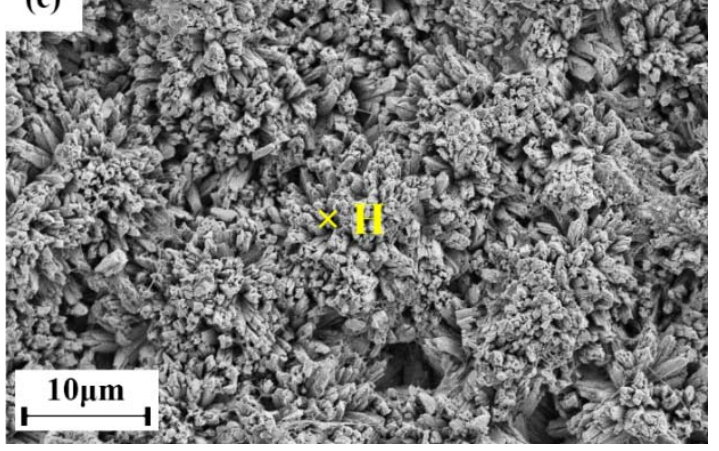

Figure 8. Surface morphology of $304 \mathrm{SS}$ with polarization at $-0.65 \mathrm{~V}$ for $20 \mathrm{~h} \mathrm{(a),} 70 \mathrm{~h} \mathrm{(b)}$ and $168 \mathrm{~h} \mathrm{(c).}$

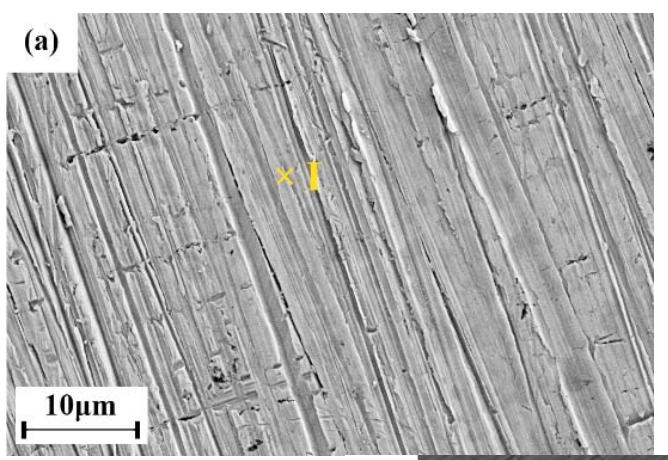

(b)

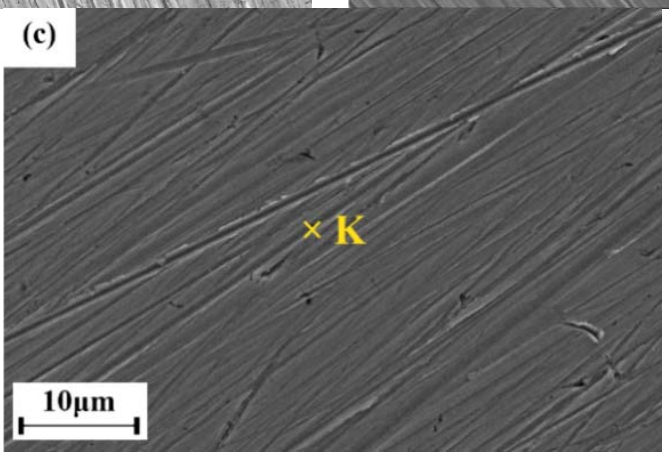

Figure 9. Surface morphology of $304 \mathrm{SS}$ with polarization at $-0.50 \mathrm{~V}$ for $20 \mathrm{~h} \mathrm{(a),} 70 \mathrm{~h} \mathrm{(b)}$ and $168 \mathrm{~h} \mathrm{(c).}$

\subsubsection{EDX Analysis}

EDX spectra of 304 SS surface after polarization at $-0.80 \mathrm{~V},-0.65 \mathrm{~V}$, and $-0.50 \mathrm{~V}$ for different time were recorded for the marked positions from A to K shown in Figures 7-9. The main elements at the marked locations on the surface of polarized 304 SS are shown in Figure 10. 

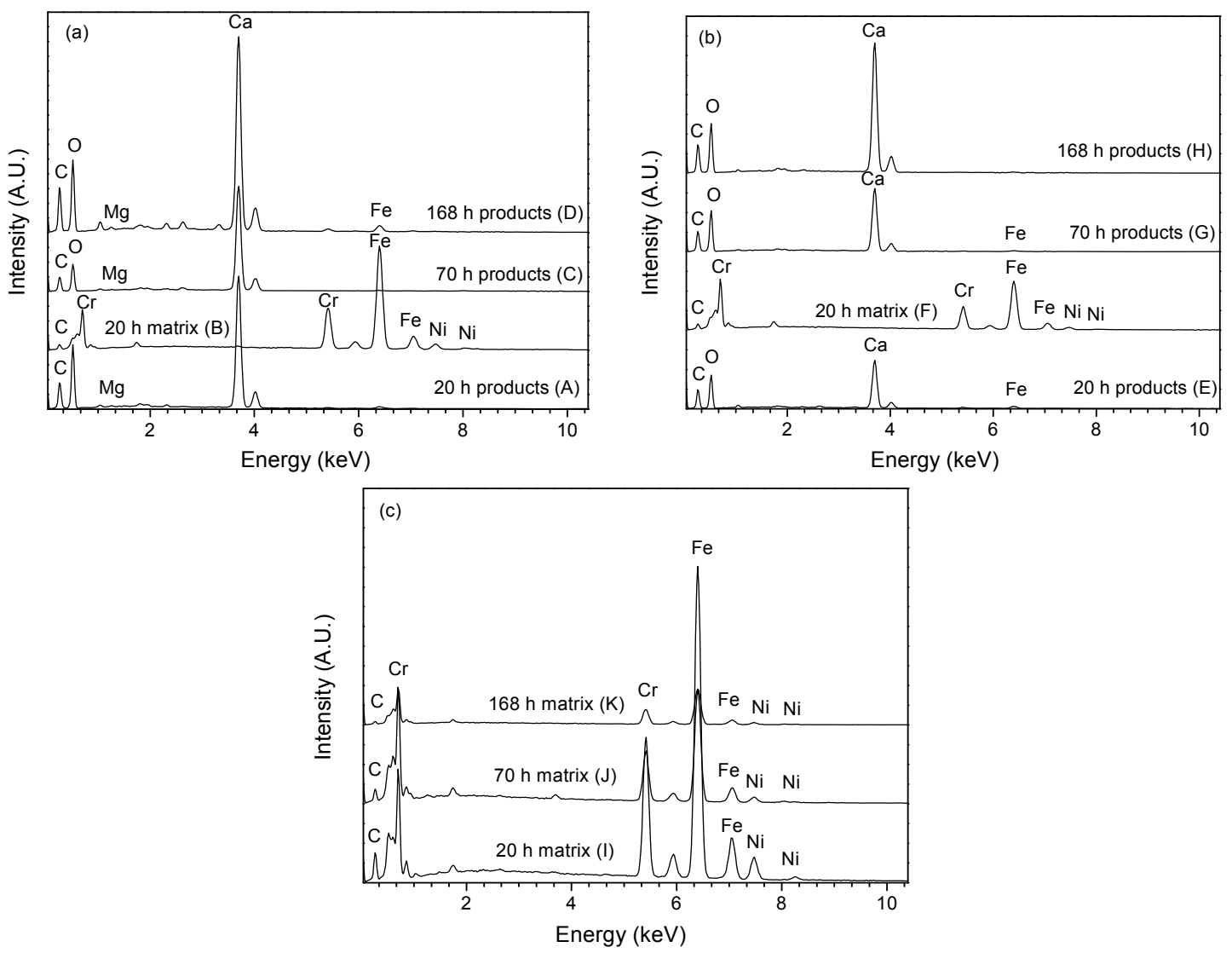

Figure 10. EDX spectra of 304 SS after cathodic polarization for different time in sea water at $-0.80 \mathrm{~V}$ (a), $-0.65 \mathrm{~V}(\mathbf{b})$, and $-0.50 \mathrm{~V}(\mathbf{c})$.

For the position marked A, the elements $\mathrm{C}, \mathrm{O}, \mathrm{Ca}, \mathrm{Mg}$, Fe were detected. Note it has a high $\mathrm{Ca}$ peak with tracing $\mathrm{Mg}$ element, which means that the deposits on $304 \mathrm{SS}$ with polarization at $-0.80 \mathrm{~V}$ in sea water for $20 \mathrm{~h}$ consist of Ca-containing composites predominantly and few Mg-containing composites. The weak Fe signal may come from the metal substrate. Although the presence of co-deposit of $\mathrm{Mg}(\mathrm{OH})_{2}$ together with iron hydroxide as the thin base layer well before precipitation of $\mathrm{CaCO}_{3}$ on steel has been reported in the literature [5], the calcareous deposits formed at $-0.65 \mathrm{~V}$ without any $\mathrm{Mg}$ element indicate that there is no such co-deposit containing $\mathrm{Mg}$ and Fe precipitated as a base layer on $304 \mathrm{SS}$. Hence, the Fe element is not from the deposit itself. For position B without precipitated particles, only obvious signals of $\mathrm{Fe}, \mathrm{Cr}$, and $\mathrm{Ni}$ were detected, which comes from the 304 SS surface. The position C and D, corresponding to polarization at $-0.80 \mathrm{~V}$ for $70 \mathrm{~h}$ and $168 \mathrm{~h}$ respectively, presented somewhat high peaks of $\mathrm{Ca}$ and $\mathrm{Mg}$ as compared with the position $\mathrm{A}$, which can be ascribed to the growth of the calcareous deposits with cathodic polarization. It should be noted from Figure 10 that only the deposits formed by polarization at $-0.80 \mathrm{~V}$ contained the $\mathrm{Mg}$ element. Usually, magnesium hydroxide precipitates in sea water at a critical $\mathrm{pH}$ value as high as 9.3 or more $[5,44]$. This implies that applied polarization at $-0.80 \mathrm{~V}$ can result in local environment of high $\mathrm{pH}$ at the interface of metal and electrolyte, which promotes the deposit of $\mathrm{Mg}(\mathrm{OH})_{2}$.

With polarization at the potential of $-0.65 \mathrm{~V}$, the calcareous deposits are the only Ca-containing compound $\left(\mathrm{CaCO}_{3}\right.$ determined by $\mathrm{XRD}$ ) without the $\mathrm{Mg}$ element (see spectra at location $\mathrm{E}, \mathrm{F}, \mathrm{G}, \mathrm{H}$ in Figure 10). The spectrum at the position $\mathrm{F}$ is almost the same as the position $\mathrm{B}$. The somewhat high content of $\mathrm{Fe}$ and $\mathrm{Cr}$ at the position $\mathrm{E}$, which obviously comes from the metal substrate, demonstrates that the deposit is thin at $20 \mathrm{~h}$ of cathodic polarization. With polarization for $168 \mathrm{~h}$, the deposits of $\mathrm{CaCO}_{3}$ become thick as no metal element from $304 \mathrm{SS}$ substrate can be detected (see the spectrum of location $\mathrm{H})$. 
For the samples with polarization at $-0.50 \mathrm{~V}$, only elements of $\mathrm{Fe}, \mathrm{C}, \mathrm{Cr}$, and $\mathrm{Ni}$ were found on the surface, implying that calcareous deposit cannot be formed at $-0.50 \mathrm{~V}$ for the whole test period. This result is consistent with that of Eashwar [31], that calcareous deposit can be precipitated if the potential is more negative than $-0.67 \mathrm{~V}$ on stainless steel.

\subsubsection{XRD Analysis}

Figure 11 shows the XRD patterns of $304 \mathrm{SS}$ electrodes after polarization at potential of $-0.80 \mathrm{~V}$, $-0.65 \mathrm{~V}$, and $-0.50 \mathrm{~V}$ for $168 \mathrm{~h}$. The constituent of calcareous deposits formed at $-0.65 \mathrm{~V}$ and $-0.80 \mathrm{~V}$ was found to be aragonite $\left(\mathrm{CaCO}_{3}\right)$. No phase of $\mathrm{Mg}(\mathrm{OH})_{2}$ was present for the sample with polarization at $-0.80 \mathrm{~V}$ though a little $\mathrm{Mg}$ element was detected by EDX analysis. There was no evidence to show the existing of Ca or Mg related substances on the polarized $304 \mathrm{SS}$ surface after $168 \mathrm{~h}$ at $-0.50 \mathrm{~V}$, where only the phase in 304 SS was detected.

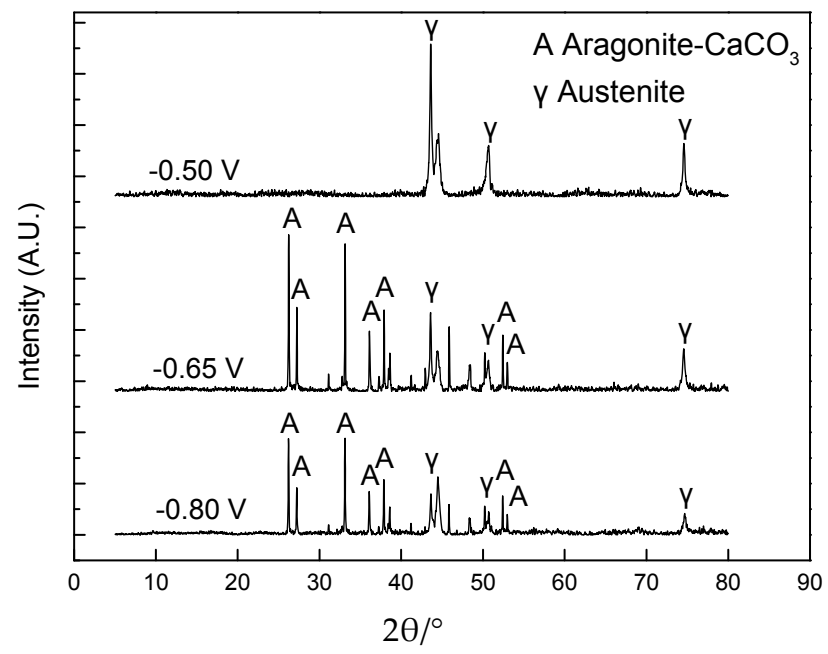

Figure 11. XRD patterns of 304 SS after cathodic polarization for $168 \mathrm{~h}$ in sea water at different potentials.

\subsection{Discussion}

The mechanism for the formation of calcareous deposit under cathodic protection has well been documented $[18,24-26,29]$. The oxygen reduction is the dominating reaction on the metal surface at the potential from $-0.50 \mathrm{~V}$ to $-0.80 \mathrm{~V}$ without hydrogen evolution. The reaction of oxygen reduction increases the concentration of $\mathrm{OH}^{-}$in the electrolyte adjacent to the metal surface. As the $\mathrm{pH}$ value in the electrolyte exceeds some critical values, the calcareous deposit precipitates on the surface with the formation and growth of nuclei of crystal particles. From SEM observation of the surface of 304 SS with cathodic polarization, it can be found that the calcareous deposit does not precipitate at $-0.50 \mathrm{~V}$, indicating that the small polarization current cannot form an enough high $\mathrm{pH}$ environment adjacent to the surface. However, the high current density at the first stage of polarization at $-0.80 \mathrm{~V}$ can easily escalate the $\mathrm{pH}$ close to the surface to the critical value, promoting the formation of the calcareous deposits.

Cathodic polarization affects not only the calcareous deposit, but also the oxide film on the stainless steel. Generally, the passive film can be formed spontaneously on the surface of stainless steel due to high content of alloy elements of $\mathrm{Cr}, \mathrm{Ni}$ and so on. After finishing the surface with abrasive paper, there is still a thin oxide film on the surface of the stainless steel sample as revealed by the $R_{\mathrm{ox}}$ for the fresh sample before cathodic polarization. The passive film of stainless steel generally has a bilayer structure, with the outermost layer of oxide/hydroxide enriched in iron, and an inner layer predominantly rich in chromium and nickel oxides [43,45-48]. Cathodic polarization damages the protective layer with reduction reactions of the oxide film, especially the ferric oxide $[16,33]$. 
However, the passive film cannot be removed completely from the 304 SS surface even with strong cathodic polarization at the potential of $-1.5 \mathrm{~V}$ [30]. The resistance of passive film is proportional to the thickness of the film and the specific resistivity of the passive layer [30]. The reduction of oxides can weaken the stability and reduce the thickness of the film by dissolution. It can also decrease the resistivity of the film with the composition and structure of oxides changed [13]. Therefore, it is reasonable to attribute the decrease of $R_{\mathrm{ox}}$ at the first stage of polarization at $-0.80 \mathrm{~V}$ to the reduction of the passive film [34-37].

When the 304 SS is polarized at the potential of $-0.80 \mathrm{~V}$ in sea water, the reaction of oxygen reduction on the passivated surface occurs simultaneously with the reduction of the ferric oxide in the passive film [33]. The circulation of cathodic current induces a $\mathrm{pH}$ shift towards alkaline values which promotes the growth of calcareous deposits $[5,15,22]$ and enhances the repair of the reduced oxide film on the surface [41-43].

It is known that stainless steel has excellent corrosion resistance in the alkaline solution with high $\mathrm{pH}$ value [43,49-51], which is related to a thin but very protective oxide film formed on the surface. Therefore, the $R_{\mathrm{ox}}$ increases with the continuing cathodic polarization at the later stage.

It can be seen from the EIS analysis that the surface variation of 304 SS is consistent with the change of current density observed in chronoamperometry experiments at the polarization potentials. With polarization at $-0.50 \mathrm{~V}$, the $304 \mathrm{SS}$ can be protected at low current density due to the growth of passive film with high resistance, though calcareous deposits cannot be formed. When the sample is polarized at $-0.80 \mathrm{~V}$, the protective current density is lower than that at $-0.65 \mathrm{~V}$, but higher than that at $-0.50 \mathrm{~V}$, due to the coverage of relatively compact calcareous deposits on the surface. With polarization at $-0.80 \mathrm{~V}$ and $-0.65 \mathrm{~V}$, the 304 SS changes its surface with oxide film reduced at first and then repaired as the adjacent $\mathrm{pH}$ value is increased. Once the cathodic protection is interrupted, the calcareous deposit can still protect the covered substrate by isolation effect, while the exposed surface without deposit or under porous deposit will suffer corrosion attacked by chloride ions in sea water. The repassivated surface has better corrosion resistance than the surface with oxide film reduced.

According to ISO 15589-2 [52], the recommended potential criteria of cathodic protection for austenite stainless steel like $304 \mathrm{SS}$ are $-0.50 \mathrm{~V}$ as the minimum negative potential and $-1.10 \mathrm{~V}$ as the maximum negative potential. For stainless steel of high strength like precipitated martensite steel, potential more negative than $-0.80 \mathrm{~V}$ shall be avoided to prevent hydrogen embrittlement. To obtain proper protection of a stainless-steel propeller shaft-stern tube assembly, Lorenzi et al. used galvanic anodes of carbon steel in order to achieve the required criterion of cathodic protection [1]. Sarlak et al. investigated calcareous deposit formed on 316 stainless steel with different cathodic potentials [26], finding that the deposit with polarization at $-0.95 \mathrm{~V}$ was dominated with Ca-rich phase and a low amount of brucite. At more cathodic values, a less protective deposit with greater amount of brucite usually forms. Eashwar et al. studied the cathodic behavior of stainless steel in coastal Indian seawater and concluded that a potential of about $-0.70 \mathrm{~V}$ should provide optimum protection of $316 \mathrm{SS}$ in warmer, full strength seawater that supports the precipitation of calcareous deposits [31]. The suitable potential of cathodic protection for stainless steel depends on the specific situation. The optimal cathodic protection potential emerging by results presented in this study is $-0.50 \mathrm{~V}$ for $304 \mathrm{SS}$ in sea water, especially for those moving parts, considering the small current density, high resistance of passive film and no calcareous deposit. It should be noted that this result was derived during laboratory testing, and the situation for engineering application appears more complicated because the optimization of potential is influenced by many other factors, such as flow rate, temperature and chemistry of sea water, and biofouling.

\section{Conclusions}

Type 304 SS was polarized in sea water at $-0.80 \mathrm{~V}$ vs. SCE, $-0.65 \mathrm{~V}$ vs. SCE and $-0.50 \mathrm{~V}$ vs. SCE. Chronoamperometry, EIS, SEM, EDX, and XRD were used to investigate the evolution of calcareous deposits and passive film on the surface. The conclusions can be drawn as below. 
- Type 304 SS can be protected effectively from corrosion with cathodic polarization at all the tested potentials. The current density needed for keeping the polarization at $-0.80 \mathrm{~V}$ vs. SCE was smaller than that for maintaining the polarization at $-0.65 \mathrm{~V}$ vs. SCE, in relation to the formation of more compact calcareous deposits and the higher resistance of the passive film. This investigation suggests that among the tested potentials, the optimal one for cathodic protection of $304 \mathrm{SS}$ in sea water is $-0.50 \mathrm{~V}$ vs. SCE, especially for moving parts, with a compromise among the effects over the passive film, calcareous deposits, and protective current density.

- The analyses by EIS, SEM, EDX and XRD demonstrated that calcareous deposits were formed on $304 \mathrm{SS}$ at $-0.80 \mathrm{~V}$ vs. SCE and $-0.65 \mathrm{~V}$ vs. SCE, not at $-0.50 \mathrm{~V}$ vs. SCE. A longer polarization was needed to produce calcareous deposits at $-0.65 \mathrm{~V}$ vs. SCE than that at $-0.80 \mathrm{~V}$ vs. SCE. The deposits formed at $-0.80 \mathrm{~V}$ vs. SCE consisted of $\mathrm{CaCO}_{3}$ predominantly and a small amount of Mg-containing substances, while the precipitates produced at $-0.65 \mathrm{~V}$ vs. SCE contained only $\mathrm{CaCO}_{3}$. The $\mathrm{CaCO}_{3}$ phase was aragonite.

- With polarization at $-0.80 \mathrm{~V}$ vs. SCE and $-0.65 \mathrm{~V}$ vs. SCE, the resistance of passive film on 304 SS decreased initially and then increased, in relation to the reduction of the oxide film and its successive repair. For the stainless steel with polarization at $-0.50 \mathrm{~V}$ vs. SCE, the film resistance increased with polarization time, indicating that the oxide film is not reduced at this potential. The dominant cathodic reaction at $-0.50 \mathrm{~V}$ vs. SCE is the oxygen reduction, which elevates the $\mathrm{pH}$ value adjacent to the surface, promoting the growth of the oxide film.

Author Contributions: L.X. designed the experiments and revised the manuscript; T.S. performed the experiments, analyzed the data and wrote part of the paper; G.H. analyzed the data and wrote the paper; P.L. and L.M. carried out the partial analysis work.

Funding: This work is financially supported by the Taishan Scholars Project of Shandong Province, the Research Project of Technical Basis of National Defense, and the National Natural Science Foundation of China (No. 51401185).

Acknowledgments: The authors are grateful to LSMRI for permission to publish this article.

Conflicts of Interest: The authors declare no conflict of interest.

\section{References}

1. Lorenzi, S.; Pastore, T.; Bellezze, T.; Fratesi, R. Cathodic protection modelling of a propeller shaft. Corros. Sci. 2016, 108, 36-46. [CrossRef]

2. Dong, C.F.; Luo, H.; Xiao, K.; Sun, T.; Liu, Q.; Li, X.G. Effect of temperature and $\mathrm{Cl}^{-}$concentration on pitting of 2205 duplex stainless steel. J. Wuhan Univ. Technol. 2011, 26, 641-647. [CrossRef]

3. Wigen, S.W.; Osvoll, H.; Gartland, P.O.; Huang, W.J. Efficient cathodic protection of stainless steel small bore tubing. In Proceedings of the Corrosion 2007, Nashville, TN, USA, 11-15 March 2007; Paper No. 07078.

4. Zhang, Y.; Wang, J.Z.; Yin, X.Y.; Yan, F.Y. Tribocorrosion behaviour of 304 stainless steel in different corrosive solutions. Mater. Corros. 2016, 67, 769-777. [CrossRef]

5. Yang, Y.F.; Scantlebury, J.D.; Koroleva, E.V. A study of calcareous deposits on cathodically protected mild steel in artificial seawater. Metals 2015, 5, 439-456. [CrossRef]

6. Mancia, F.; Tamba, A. Slow strain rate stress corrosion cracking of AISI 304 Stainless Steel in $\mathrm{NaCl}$ solution and its prevention by controlled cathodic protection. Corrosion 1986, 42, 362-367. [CrossRef]

7. Eashwar, M.; Kumar, P.S.; Ravishankar, R.G. Subramanian Sunlight enhances calcareous deposition on cathodic stainless steel in natural seawater. Biofouling 2013, 29, 185-193. [CrossRef] [PubMed]

8. Orfei, L.H.; Simison, S.; Busalmen, J.P. Stainless steels can be cathodically protected using energy stored at the marine sediment/seawater interface. Environ. Sci. Technol. 2006, 40, 6473-6478. [CrossRef] [PubMed]

9. Zucchi, F.; Grassi, V.; Monticelli, C.; Trabanelli, G. Hydrogen embrittlement of duplex stainless steel under cathodic protection in acidic artificial sea water in the presence of sulphide ions. Corros. Sci. 2006, 48, 522-530. [CrossRef]

10. BS EN 12954 Cathodic Protection of Buried or Immersed Metallic Structures-General Principles and Application for Pipelines; British Standards Institution: London, UK, 2011. 
11. Heselmans, J.; Buijs, N.W.; Isaac, E. Sacrificial Anodes for Protection of Seawater Pump Caissons against Galvanic Corrosion. In Proceedings of the Corrosion 2011, Houston, TX, USA, 13-17 March 2011; Paper No. 11056.

12. Collazo, A.; Izquierdo, M.; Novoa, X.R.; Perez, C. Surface treatment of carbon steel substrates to prevent cathodic delamination. Electrochim. Acta 2007, 52, 7513-7518. [CrossRef]

13. Yao, J.Z.; Dong, C.F.; Man, C.; Xiao, K.; Li, X.G. The electrochemical behavior and characteristics of passive film on 2205 duplex stainless steel under various hydrogen charging conditions. Corrosion 2016, 72, 42-50. [CrossRef]

14. Addari, D.; Elsener, B.; Rossi, A. Electrochemistry and surface chemistry of stainless steels in alkaline media simulating concrete pore solutions. Electrochim. Acta 2008, 53, 8078-8086. [CrossRef]

15. Bozec, N.L.; Compère, C.; Her, M.L.; Laouenan, A.; Costa, D.; Marcus, P. Influence of stainless steel surface treatment on the oxygen reduction reaction in seawater. Corros. Sci. 2001, 43, 765-786. [CrossRef]

16. Freire, L.; Carmezim, M.J.; Ferreira, M.G.S.; Montemor, M.F. The electrochemical behaviour of stainless steel AISI 304 in alkaline solutions with different $\mathrm{pH}$ in the presence of chlorides. Electrochim. Acta 2011, 56, 5280-5289. [CrossRef]

17. Burkhard, H.; Kirchheim, R. Dissolution rates of iron and chromium and FeCr alloys in the passive state. Corros. Sci. 1990, 31, 533-538.

18. Moller, $\mathrm{H}$. The influence of $\mathrm{Mg}^{2+}$ on the formation of calcareous deposits on a freely corroding low carbon steel in seawater. Corros. Sci. 2007, 49, 1992-2001. [CrossRef]

19. Rousseau, C.; Baraud, F.; Leleyter, L.; Jeannin, M.; Gil, O. Kaolinite influence on calcareous deposit formation. Electrochim. Acta 2009, 55, 196-203. [CrossRef]

20. Rousseau, C.; Baraud, F.; Leleyter, L.; Jeannin, M.; Gil, O. Calcareous deposit formed under cathodic protection in the presence of natural marine sediments: A 12 months experiment. Corros. Sci. 2010, 52, 2206-2218. [CrossRef]

21. Sun, W.; Liu, G.C.; Wang, L.D.; Li, Y. A mathematical model for modeling the formation of calcareous deposits on cathodically protected steel in seawater. Electrochim. Acta 2012, 78, 597-608. [CrossRef]

22. Barchiche, C.; Deslouis, C.; Festy, D.; Gil, O.; Refait, Ph.; Touzain, S.; Tribollet, B. Characterization of calcareous deposits in artificial seawater by impedance techniques: 3-Deposit of $\mathrm{CaCO}_{3}$ in the presence of Mg(II). Electrochim. Acta 2003, 48, 1645-1654. [CrossRef]

23. Solis, J.L.; Genesca, J. Influence of calcareous deposits on galvanic CP in seawater. Mater. Perform. 2011, 50, 34-38.

24. Carre, P.; Gunkel-Grillon, P.; Serres, A.; Jeannin, M.; Sabot, R.; Quiniou, T. Calcareous electrochemical precipitation, a new method to trap nickel in seawater. Environ. Chem. Lett. 2017, 15, 151-156. [CrossRef]

25. Hoseinieh, S.M.; Shahrabi, T.; Ramezanzadeh, B.; Rad, M.F. Influence of sweet crude oil on nucleation and corrosion resistance of calcareous deposits. J. Mater. Eng. Perform. 2016, 25, 4805-4811. [CrossRef]

26. Sarlak, M.; Shahrab, T.; Zmanzada, M. Investigation of calcareous deposits formation on copper and 316L stainless steel under cathodic polarization in artificial seawater. Prot. Met. Phys. Chem. Surf. 2009, 45, 216-222. [CrossRef]

27. Smith, S.W. Analysis of the cathodic behavior of aluminum in nature sea water by surface chemistry. Corrosion 1981, 37, 105-121.

28. Yan, J.F.; White, R.E.; Griffin, R.B. Parametric studies of the formation of calcareous deposits on cathodically protected steel in seawater. J. Electrochem. Soc. 1993, 140, 1275-1280. [CrossRef]

29. Hartt, W.H.; Culberson, C.H.; Smith, S.W. Calcareous deposits on metal surfaces in seawater-A critical review. Corrosion 1984, 40, 609-618. [CrossRef]

30. Barchiche, Ch.; Deslouis, C.; Gil, O.; Refait, Ph.; Tribollet, B. Characterisation of calcareous deposits by electrochemical methods: Role of sulphates, calcium concentration and temperature. Electrochim. Acta 2004, 49, 2833-2839. [CrossRef]

31. Eashwar, M.; Subramanian, G.; Palanichamy, S.; Rajagopal, G.; Madhu, S.; Kamaraj, P. Cathodic behaviour of stainless steel in coastal Indian seawater: Calcareous deposits overwhelm biofilms. Biofouling 2009, 25, 191-201. [CrossRef] [PubMed]

32. De Saravia, S.G.G.; de Mele, M.F.L.; Videla, H.A.; Edyvean, R.G.J. Bacterial biofilms on cathodically protected stainless steel. Biofouling 1997, 11, 1-17. [CrossRef] 
33. Liu, C.T.; Wu, J.K. Influence of $\mathrm{pH}$ on the passivation behaviour of $254 \mathrm{SMO}$ stainless steel in $3.5 \% \mathrm{NaCl}$ solution. Corros. Sci. 2007, 49, 2198-2209. [CrossRef]

34. Liu, X.H.; Han, E.H.; Wu, X.Q. Effects of $\mathrm{pH}$ value on characteristics of oxide films on 316L stainless steel in Zn-injected borated and lithiated high temperature water. Corros. Sci. 2014, 78, 200-207. [CrossRef]

35. Luo, H.; Dong, C.F.; Li, X.G.; Xiao, K. The electrochemical behaviour of 2205 duplex stainless steel in alkaline solutions with different $\mathrm{pH}$ in the presence of chloride. Electrochim. Acta 2012, 64, 211-220. [CrossRef]

36. Luo, H.; Su, H.Z.; Dong, C.F.; Li, X.G. Passivation and electrochemical behavior of 316L stainless steel in chlorinated simulated concrete pore solution. Appl. Surf. Sci. 2017, 400, 38-48. [CrossRef]

37. Ramasubramanian, N.; Preocanin, N.; Davidson, R.D. Analysis of passive films on stainless steel by cyclic voltammetry and auger spectroscopy. J. Electrochem. Soc. 1985, 16, 793-798. [CrossRef]

38. Karoui, H.; Riffault, B.; Jeannin, M.; Kahoul, A.; Gil, O.; Amor, M.B.; Tlili, M.M. Electrochemical scaling of stainless steel in artificial seawater: Role of experimental conditions on $\mathrm{CaCO}_{3}$ and $\mathrm{Mg}(\mathrm{OH})_{2}$ formation. Desalination 2013, 311, 234-240. [CrossRef]

39. Neville, A.; Morizot, A.P. Calcareous scales formed by cathodic protection-An assessment of characteristics and kinetics. J. Cryst. Growth 2002, 243, 490-502. [CrossRef]

40. Mohammadi, F.; Nickchi, T.; Attar, M.M.; Alfantazi, A. EIS study of potentiostatically formed passive film on 304 stainless steel. Electrochim. Acta 2011, 56, 8727-8733. [CrossRef]

41. Ge, H.H.; Zhou, G.D.; Wu, W.Q. Passivation model of 316L stainless steel in simulated cooling water and the effect of sulfide on the passive film. Appl. Surf. Sci. 2003, 211, 321-334. [CrossRef]

42. Metikoš-Huković, M.; Babić, R.; Grubač, Z.; Petrovićet, Z.; Lajçi, N. High corrosion resistance of austenitic stainless steel alloyed with nitrogen in an acid solution. Corros. Sci. 2011, 53, 2176-2183. [CrossRef]

43. Hirschorn, B.; Orazem, M.E.; Tribollet, B.; Vivier, V.; Frateur, I.; Musiani, M. Determination of effective capacitance and film thickness from constant-phase-element parameters. Electrochim. Acta 2010, 55, 6218-6227. [CrossRef]

44. Lewandowski, Z.; Lee, W.C.; Characklis, W.G.; Little, B.J. Dissolved oxygen and pH microelectrode measurements at water-immersed metal surfaces. Corrosion 1989, 45, 92-98. [CrossRef]

45. Rondelli, G.; Torricelli, P.; Fini, M.; Giardino, R. In vitro corrosion study by EIS of a nickel-free stainless steel for orthopaedic applications. Biomaterials 2005, 26, 739-744. [CrossRef] [PubMed]

46. Muñoz, A.I.; Julián, L.C. Influence of electrochemical potential on the tribocorrosion behaviour of high carbon CoCrMo biomedical alloy in simulated body fluids by electrochemical impedance spectroscopy. Electrochim. Acta 2010, 55, 5428-5439. [CrossRef]

47. Blanco, G.; Bautista, A.; Takenouti, H. EIS study of passivation of austenitic and duplex stainless steels reinforcements in simulated pore solutions. Cem. Concr. Compos. 2006, 28, 212-219. [CrossRef]

48. Veleva, L.; Alpuche-Aviles, M.A.; Graves-Brook, M.K.; Wipf, D.O. Comparative cyclic voltammetry and surface analysis of passive films grown on stainless steel 316 in concrete pore model solutions. J. Electroanal. Chem. 2002, 537, 85-93. [CrossRef]

49. Bautista, A.; Blanco, G.; Velasco, F.; Gutiérrez, A.; Soriano, L.; Palomares, F.J.; Takenouti, H. Changes in the passive layer of corrugated austenitic stainless steel of low nickel content due to exposure to simulated pore solutions. Corros. Sci. 2009, 51, 785-792. [CrossRef]

50. Freire, L.; Carmezim, M.J.; Ferreira, M.G.S.; Montemor, M.F. The passive behaviour of AISI 316 in alkaline media and the effect of $\mathrm{pH}$ : A combined electrochemical and analytical study. Electrochim. Acta 2010, 55, 6174-6181. [CrossRef]

51. Freire, L.; Catarino, M.A.; Godinho, M.I.; Ferreira, M.J.; Ferreira, M.G.S.; Simões, A.M.P.; Montemor, M.F. Electrochemical and analytical investigation of passive films formed on stainless steels in alkaline media. Cem. Concr. Compos. 2012, 34, 1075-1081. [CrossRef]

52. ISO 15589-2 Petroleum, Petrochemical and Natural Gas Industries-Cathodic Protection of Pipeline Transportation Systems-Part 2: Offshore Pipelines; International Organization for Standardization: Vernier, Geneva, Switzerland, 2012.

(C) 2018 by the authors. Licensee MDPI, Basel, Switzerland. This article is an open access article distributed under the terms and conditions of the Creative Commons Attribution (CC BY) license (http:/ / creativecommons.org/licenses/by/4.0/). 